\title{
Effect of cricoid pressure on laryngoscopic view and ease of intubation with Airtraq ${ }^{\circledR}$ laryngoscope
}

\author{
S Mathew ${ }^{1}$, A K Handigodu Duggappa ${ }^{1 *}$, S Muhamed ${ }^{2}$, N Shetty ${ }^{1}$, R Krishna ${ }^{I}$, AA Samad ${ }^{3}$ \\ Associate Professor ${ }^{1 *}$, Assistant Professor ${ }^{2}$, Junior Resident ${ }^{3}$, Department of Anaesthesia, Kasturba \\ Medical College, Manipal, Karnataka, India.
}

(The order of the authors was changed on $6^{\text {th }}$ December 2017 due to an editorial error)

Background: Improved laryngeal view has made Airtraq ${ }^{\circledR}$ optical laryngoscope suitable for rapid sequence induction and intubation, provided this important advantage is not lost with application of cricoid pressure (CP). This study was designed to investigate the effect of $\mathrm{CP}$ on laryngoscopic view and to ascertain the ease of orotracheal intubation using Airtraq ${ }^{\circledR}$ laryngoscope.

Material and Methods: In this prospective randomized study, fifty patients of either gender aged 18-60yrs were randomly allocated into two groups. In Group CP, orotracheal intubation was performed using Airtraq ${ }^{\circledR}$ laryngoscope and application of CP. In Group NCP intubation was performed without application of CP. Laryngoscopic view, success, ease, duration and number of attempts at intubation were recorded.

Results: In 49 out of 50 patients included in the study, CP lead to insignificant or no change in POGO score. In Group CP, 21 out of 25 patients had easy intubation, whereas in Group NCP, 23 out of 25 patients had easy intubation. Two patients in both groups had a slightly difficult intubation. Two patients had difficulty in intubation in Group CP, whereas none of the patients in Group NCP had difficulty in intubation.

Conclusion: During Airtraq ${ }^{\circledR}$ assisted intubation in patients with normal airways, application of $\mathrm{CP}$ does not produce any clinically significant change in the laryngoscopic view and time required for intubation. However, in cases where application of $\mathrm{CP}$ causes hindrance in intubation despite adequate laryngeal view, we recommend release of $\mathrm{CP}$ to facilitate intubation.

Keywords: Airtraq; cricoid pressure; intubation

\section{Introduction}

The technique of rapid sequence induction with application of cricoid pressure (CP) was evolved to protect the airway from aspiration, in patients with full stomach requiring emergency surgeries. Currently there is insufficient evidence to advocate or abandon the use of $\mathrm{CP}$ to prevent passive regurgitation in at-risk anaesthetised patients. ${ }^{1,2,3}$

\section{*Correspondence: A K Handigodu \\ Duggappa \\ E mail: arunhd2000@yahoo.com}

Received: 02/06/2017

Accepted: 19/06/2017

DOI: 10.4038 /slja.v25i2.8244
The requirement for novel airway devices that increase the ease of tracheal intubation, particularly in settings where laryngoscopy is likely to be difficult, has spurred the invention of several instruments including videolaryngoscopes and optical laryngoscopes. ${ }^{4}$ The Airtraq ${ }^{\circledR}$ (Prodol Ltd., Vizcaya, Spain) is an indirect laryngoscope that has been designed to improve glottic visualisation compared to Macintosh laryngoscope enabling it suitable for rapid sequence induction and intubation, provided this important advantage is not lost with the application of CP. ${ }^{5}$ Thus, the present study was designed to study the effect of $\mathrm{CP}$ on the laryngoscopic view and to ascertain the ease of orotracheal intubation with the aid of Airtraq ${ }^{\circledR}$ laryngoscope. 


\section{Subjects and Methods}

This study was a prospective, blinded and randomized clinical trial. After obtaining institutional ethics committee approval, 50 patients of either gender aged 18-60yrs belonging to American Society of Anaesthesiologists Physical Status (ASA-PS) I or II with modified Mallampati class I and II airway, undergoing elective surgery requiring general anaesthesia and orotracheal intubation were randomly allocated (computer generated randomization table) into two groups of 25 patients (Group CP and Group NCP). Exclusion criteria included patients at risk for gastric aspiration, anticipated difficult airway, history of surgery in the neck, pharynx or larynx, BMI $>30$ $\mathrm{kg} / \mathrm{m}^{2}$, reactive airway disease and cervical spine pathology.

In Group CP patients orotracheal intubation was performed using Airtraq ${ }^{\circledR}$ laryngoscope and application of $\mathrm{CP}$ whereas in Group NCP orotracheal intubation was performed using Airtraq ${ }^{\circledR}$ laryngoscope without application of CP. There were 4 observers in the study. Observer 1 was the resident who evaluated the patients preoperatively and applied CP. Observer 2 was the consultant who is experienced in intubation with Airtraq ${ }^{\circledR}$ laryngoscope, assessed the laryngoscopic vie was percentage of glottic opening (POGO)score and intubated all the patients. Observer 3 was an additional consultant who also assessed the laryngoscopic view as POGO score. Anaesthesiology technician who recorded the intubation time was observer 4 .

Preoperative evaluation of the patients was done on the day prior to surgery, written informed consent obtained and anxiolytic premedication given. Patients were kept nil orally, 6hrs for solids and $2 \mathrm{hrsfor}$ clear fluids. Inside the operating room, intravenous access was established and preinduction monitoring commenced using 5-lead electrocardiography, NIBP, pulse oximetry, capnography and peripheral nerve stimulator (PNS). The patient was preoxygenated with $100 \%$ oxygen for $3 \mathrm{~min}$ and placed in sniffing position. Anaesthesia was induced with fentanyl $1.5-2 \mu \mathrm{g} / \mathrm{kg}$ and propofol $2.5-3 \mathrm{mg} / \mathrm{kg}$ i.v. After checking the adequacy of mask ventilation, neuromuscular blockade was achieved with vecuronium bromide
$0.1 \mathrm{mg} / \mathrm{kg}$ i.v. and anaesthesia deepened with $1.5 \%$ to $2 \%$ isoflurane in oxygen. After ensuring complete neuromuscular blockade by train-of- four count of $0 / 4$ on PNS, laryngoscopy and intubation was performed as per group allocation.

Observer 1 was trained to apply a $3.5 \mathrm{~kg}(30-40 \mathrm{~N})$ force using three finger technique (thumb, index and middle fingers) on an infant weighing scale before commencing the study. During controlled ventilation, the observer 1 placed the fingers in the same manner as in applying $\mathrm{CP}$ without actually applying pressure.

Laryngoscopy and tracheal intubation was performed by observer 2 who was unaware of the group allocation. In order to blind observer 2 and 3, a screen was placed to separate them from observer 1 who was applying $\mathrm{CP}$ and the hand position for the $\mathrm{CP}$ was maintained throughout the intubation procedure in both groups, even when $\mathrm{CP}$ was not applied.

In Group $\mathrm{CP}$, the Airtraq ${ }^{\circledR}$ laryngoscope was inserted in the midline and the POGO score was assessed by observers 2 and 3 without the application of $\mathrm{CP}$ and average of the two POGO scores were taken. The POGO score was considered to be $100 \%$ if the entire glottis was visualized from the anterior commissure to the posterior inter arytenoid notch and the POGO score was $0 \%$ if none of the glottic opening was seen. Partial visualization of the glottis was thus given a subjective score between 0 and $100 \%$. Now CP would be applied by the observer1.The POGO score would be evaluated again by both observers and CP maintained until endotracheal intubation was achieved and confirmed by capnogram. Average of POGO scores recorded by two observers was taken.

In Group NCP, the POGO score was first assessed with application of $\mathrm{CP}$ and average of two observer scores were taken. Following this CP was released, average POGO score was recorded and then intubation was done without $\mathrm{CP}$. Thus, the POGO score was noted twice in each patient in both groups. 
Portex endotracheal tube with $8.0 / 8.5 \mathrm{~mm}$ internal diameter (ID) was used in males and 7.0/7.5mm ID in females. Intubation time and the number of intubation attempts were also recorded. Observer 2 would inform observer 1 applying $\mathrm{CP}$ once the first POGO score has been recorded so that the CP could either be applied or released for the second reading and tracheal intubation was performed. (Figure 1)

Figure 1: CONSORT-Flow chart

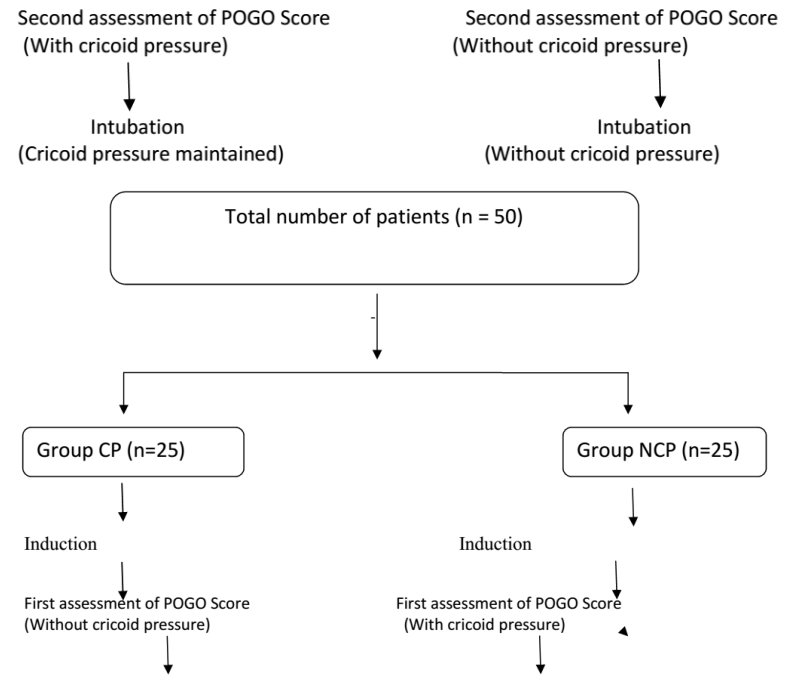

An attempt was defined as introduction of Airtraq ${ }^{\circledR}$ laryngoscope between the teeth to appearance of capnogram following intubation or withdrawal of the laryngoscope out of oral cavity. Each attempt was allowed for a maximum of $120 \mathrm{~s}$. An attempt was considered to have 'failed' if intubation was not successful, exceeded 120s or resulted in a saturation drop below 94\%. When an attempt at intubation failed, the patient was mask ventilated with isoflurane $1.5-2 \%$ in $100 \%$ oxygen and a second attempt was done with or without CP depending on the best laryngoscopic view obtained in the previous attempt. If both the laryngoscopic views were not optimal, a Macintosh laryngoscope would be used for intubation. Successful intubation was defined as appearance of square wave capnogram when ventilation was performed through the ETT. Intubation time was defined as the "time from attempting the placement of ETT from the Airtraq ${ }^{\circledR}$ channel into glottis till confirmation of intubation by capnogram".

Ease of intubation assessed during the study was described. Easy intubation is smooth passage of ETT across glottis without hinging on epiglottis or glottic inlet. Slightly difficult intubation is when the ETT hinges on glottic inlet, where as difficult intubation is inability to insert ETT in first attempt, thus requiring second attempt.

For a change of POGO score by $25 \%$, the sample size was calculated to be 25 in each group with a $90 \%$ power and an alpha error of 0.05 . For all statistical tests, $\mathrm{P}<0.05$ was considered significant. The data collected were analyzed statistically using independent samples t-test, chi-square test and Fischer's exact test. Statistical testing was conducted with statistical package for the social science system (SSPSS 15 South East Asia Bangalore).

\section{Results}

All patients from both groups completed the prospective study and were comparable with respect to age, body mass index (BMI) and gender (Table 1).

Table 1: Patient characteristics

\begin{tabular}{|l|l|l|l|}
\hline Parameters & $\begin{array}{l}\text { Group } \\
1(\mathrm{CP}) \\
(\mathrm{n}=25) \\
\text { Mean } \pm \text { SD }\end{array}$ & $\begin{array}{l}\text { Group 2 } \\
\text { (NCP) } \\
(\mathrm{n}=25) \\
\text { Mean } \pm \text { SD }\end{array}$ & P value \\
\hline Age (Years) & $\begin{array}{l}36.20 \quad \pm \\
9.23\end{array}$ & $36.04 \pm 11.10$ & $0.47^{*}$ \\
\hline BMI $\left(\mathrm{kg} / \mathrm{m}^{2}\right)$ & $\begin{array}{l}26.40 \\
1.73\end{array}$ & $26.16 \pm 1.78$ & $0.31^{*}$ \\
\hline Gender $(\mathrm{M} / \mathrm{F})$ & $12 / 13$ & $11 / 14$ & $0.39^{\dagger}$ \\
& & & \\
\hline
\end{tabular}


*Independent samples t-test

$\dagger$ Chi-square test

The changes in POGO score after the application of $\mathrm{CP}$ are shown in Table 2. The change in POGO score was considered significant when there was $>$ $25 \%$ change after application of $\mathrm{CP}$ which could either be improvement or deterioration. Application of $\mathrm{CP}$ led to deterioration in POGO score in 21 out of 50 patients. Significant change in POGO score causing deterioration in glottic visualization was observed in one amongst 50 patients after application of CP There was no change in POGO score in 17 out of 50 patients. None of the patients had significant improvement in POGO score, while eleven out of 50 patients showed improvement in POGO score by $<15 \%$ after application of CP.

Table 2: Change in POGO score with the application of $\mathrm{CP}$

\begin{tabular}{|l|l|l|l|l|l|}
\hline \multicolumn{2}{|l|}{$\begin{array}{l}\text { POGO score } \\
(\mathrm{n}=50)\end{array}$} & $\begin{array}{l}\geq \\
25\end{array}$ & $\begin{array}{l}16- \\
24\end{array}$ & $\begin{array}{l}1- \\
15\end{array}$ & $\begin{array}{l}\text { P } \\
\%\end{array}$ \\
\hline $\begin{array}{l}\text { Change in } \\
\begin{array}{l}\text { POGO } \\
\text { score }\end{array}\end{array}$ & Deterioration \\
\cline { 2 - 5 } & 1 & 4 & 16 & \multirow{2}{*}{$0.503^{*}$} \\
\hline $\begin{array}{l}\text { No change } \\
\text { in POGO } \\
\text { score }\end{array}$ & 17 & 0 & 1 & 11 & \\
\hline
\end{tabular}

Chi-square test* $\mathrm{P}<0.05 . \quad(\mathrm{S})^{*}=$ Statistically significant

Analyzing the data, application of $\mathrm{CP}$ resulted in insignificant change in POGO score among 64\% patients, no change in POGO score in $34 \%$ patients, whereas significant deterioration in POGO score in $2 \%$ cases (Figure 2 ).

Figure 2: Change in POGO score with application of $\mathrm{CP}$.

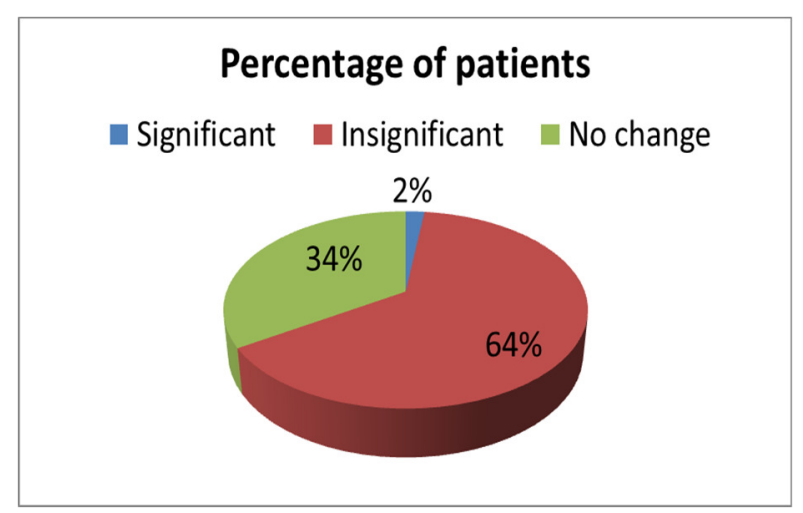

Easy intubation was noticed in $84 \%$ patients of Group CP and 94\% patients in Group NCP. However, 2 cases (8\%) had difficult intubation in Group CP whereas none of the patients had difficult intubation in Group NCP. There was no statistical difference between the two groups, $\mathrm{P}$ value being 0.546 (Table 3).

Table 3: Ease of intubation

\begin{tabular}{|l|l|l|l|l|}
\hline Group & $\begin{array}{l}\text { Easy } \\
\text { (Intubation } \\
\text { without } \\
\text { hinging at } \\
\text { glottic inlet) }\end{array}$ & $\begin{array}{l}\text { Slightly } \\
\text { difficult } \\
\text { (intubation } \\
\text { after } \\
\text { hinging at } \\
\text { glottic inlet) }\end{array}$ & $\begin{array}{l}\text { Difficult } \\
\text { (Failed } \\
\text { intubation } \\
\text { at first } \\
\text { attempt) }\end{array}$ & $\begin{array}{l}\text { P } \\
\text { value }\end{array}$ \\
\hline $\begin{array}{l}\mathrm{CP} \\
(\mathrm{n}=25)\end{array}$ & $21(84 \%)$ & $2(8 \%)$ & $2(8 \%)$ & \\
\hline $\begin{array}{l}\mathrm{NCP} \\
(\mathrm{n}=25)\end{array}$ & $23(92 \%)$ & $2(8 \%)$ & 0 & \\
\hline
\end{tabular}

*Fisher's exact test

There were no failed intubation attempts in group NCP. However, in the Group CP, there were 2 cases of failed intubation and the patients were intubated in the second attempt without application of $\mathrm{CP}$. (Table 4)

Table 4: Success of intubation and number of attempts

\begin{tabular}{|l|l|l|l|l|}
\hline Group & $\begin{array}{l}\text { Success at } \\
\text { intubation }\end{array}$ & $\begin{array}{l}\text { Failure at } \\
\text { intubation }\end{array}$ & $\begin{array}{l}\text { Number } \\
\text { of } \\
\text { attempts }\end{array}$ & $\begin{array}{l}\text { P } \\
\text { value }\end{array}$ \\
\hline
\end{tabular}




\begin{tabular}{|l|l|l|l|l|}
\hline $\begin{array}{l}\mathrm{CP} \\
(\mathrm{n}=25)\end{array}$ & $23(92 \%)$ & $2(8 \%)$ & $\begin{array}{l}\text { Two } \\
\text { attempts in } \\
\text { 2 patients, } \\
\text { one } \\
\text { attempt in } \\
23 \text { patients }\end{array}$ & $\mathbf{0 . 4 9}$ \\
\hline $\begin{array}{l}\mathrm{NCP} \\
(\mathrm{n}=25)\end{array}$ & $25(100 \%)$ & 0 & $\begin{array}{l}\text { One } \\
\text { attempt in } \\
\text { all patients }\end{array}$ & \\
\hline
\end{tabular}

*Fischer's exact test

The time taken for intubation was comparable in both the groups with $\mathrm{P}$ value of 0.24 .

Table 5: Intubation time (seconds)

\begin{tabular}{|l|l|l|}
\hline Group & $\begin{array}{l}\text { Time } \\
(\text { Mean } \pm \text { SD })\end{array}$ & P value \\
\hline $\begin{array}{l}\mathrm{CP} \\
(\mathrm{n}=25)\end{array}$ & $15.35 \pm 3.58$ & 0.24 \\
\hline $\begin{array}{l}\mathrm{NCP} \\
(\mathrm{n}=25)\end{array}$ & $13.34 \pm 3.98$ & \\
\hline
\end{tabular}

*Independent samples t-test

\section{Discussion}

Application of CP is considered to be a simple and appropriate method to protect the patient's airway from aspiration, thus rendering it an integral component of rapid sequence induction/intubation, although concerns have been raised regarding its efficacy and patient safety. ${ }^{1,2}$ The most important limitation is its interference with mask ventilation, laryngoscopy, intubation, LMA insertion and ventilation especially when higher pressure is applied. ${ }^{3,6,7,8}$

The Airtraq ${ }^{\circledR}$ is a newer airway device wherein the exaggerated curvature of blade and internal arrangement of optical components obviates the need for alignment of oral, pharyngeal and laryngeal axes for optimal glottic view, rendering it an ideal airway device in routine as well as emergency/difficult laryngoscopy and intubation scenarios. ${ }^{9,10,11,12}$
There are several studies depicting the effect of CP on glottic view and ease of intubation using conventional laryngoscopes and video laryngoscopes, whereas very few are available on the effect of CP on laryngoscopic view and ease of intubation using Airtraq ${ }^{\circledR}$ laryngoscope. ${ }^{13,14,15,16}$ Waleed Riad and Tarek Ansari in their study concluded that $\mathrm{CP}$ neither prolongs the time nor interferes with ease of intubation using Airtraq ${ }^{\circledR}{ }^{17}$

We studied the effect of $\mathrm{CP}$ on laryngoscopic view and ease of intubation with Airtraq ${ }^{\circledR}$ in 50 patients with clinically normal airway and observed that $\mathrm{CP}$ deteriorates the glottic view as evidenced by lower POGO scores during laryngoscopy. No change in glottic view on application of CP was seen in 34\% of patients, whereas $42 \%$ of the study population showed insignificant deterioration of glottic view as against the $24 \%$ who had insignificant improvement in the glottic view. In the present study, we had taken a change by 25 in the POGO score to be clinically significant, based on study by Ochroch EA et al. ${ }^{18}$ In our study change of more than 25 in POGO score was observed only in one patient (2\% of study population). This is in contrast to the findings by Corda DM et al, where they found no difference in the glottic grade with application of CP while using Glidescope. ${ }^{16}$

In our study first intubation attempt was successful in all the patients without application of $\mathrm{CP}$, while first intubation attempt failed in two patients when $\mathrm{CP}$ was applied. In both these instances the endotracheal tube could not be directed towards glottic aperture as it was repeatedly abutting against the inter arytenoid cleft. Corda DM et al in their study using Glidescope found that the glottic area reduces when CP was being applied. ${ }^{16}$ We consider the failure to intubate at first attempt in two patients when CP was applied to be clinically significant. It is possible that application of $\mathrm{CP}$ in the context of a difficult airway would have a similar effect. The significance is further increased by the fact that the same two patients could be intubated using Airtraq ${ }^{\circledR}$ once the $\mathrm{CP}$ was released, without any difficulty. In the light of the above-mentioned facts we infer that while $\mathrm{CP}$ does not affect the glottic view when using Airtraq ${ }^{\circledR}$ laryngoscope, there is a definite possibility of it making the intubation difficult and at times even impossible. We therefore 
recommend that when such a situation arises, it is advisable to release $\mathrm{CP}$ to facilitate intubation. We believe that this fact needs to be evaluated further in patients with clinically difficult airways.

Our study has certain merits. Intubation in all patients using Airtraq ${ }^{\circledR}$ was done by the same experienced consultant and in order to blind the observer 2 along with observer 3 , a screen was used to separate the observer 1 (resident applying CP). Moreover, for study purpose a wireless station was used both for POGO score assessment and intubation.

There were certain limitations in our study. We conducted the study in a limited group of patients with modified Mallampati class I and II airway, which renders us unable to project our results on effect of $\mathrm{CP}$ on higher Mallampati class. We believe that further studies are needed in patients with anticipated difficult airway. Secondly, change in $25 \%$ POGO score is subjective. Although CP was applied by the same observer in all patients to preserve uniformity, the force applied in each patient could not be assessed directly due to nonavailability of necessary instrument.

\section{Conclusion}

During Airtraq ${ }^{\circledR}$ assisted-intubation in patients with essentially normal airways, application of $\mathrm{CP}$ does not produce any clinically significant change in the laryngoscopic view and time required for intubation. However, in case where application of $\mathrm{CP}$ causes difficulty in intubation in spite of adequate glottis view, we recommend release of $\mathrm{CP}$ to facilitate intubation.

\section{References}

1. Brimacombe JR, Berry AM. Cricoid pressure review article. Can J Anaesth 1997; 44:414-25. https://doi.org/10.1007/BF03014464

PMid:9104526

2. Ovassapian A, Salem MR. Sellick's maneuver: To Do or Not Do. Anesth Analg 2009; 109:1360-62. https://doi.org/10.1213/ANE.0b013e3181b763c0 PMid:19843769

3. Kotur PF. Sellick's manoeuvre to be employed or dismissed from the armamentarium of anaesthetic practice. Indian J Anaesth 2006; 50:488.

4. Bhaskar SB. Newer airway devices: Future promising? Indian J Anaesth 2011; 55:439-41. https://doi.org/10.4103/0019-5049.89858

PMid:22174457 PMCid:PMC3237139

5. Maharaj CH, Costello JF, McDonnell JG, Harte BH, Laffey JG. The Airtraq ${ }^{\circledR}$ as a rescue airway device following failed direct laryngoscopy: a case series. Anaesthesia 2007; 62:598-601. https://doi.org/10.1111/j.1365-2044.2007.05036.x PMid:17506739

6. Hein $\mathrm{C}$, Owen $\mathrm{H}$. The effective application of cricoid pressure. Journal of Emergency Primary Health Care 2005; 3:1-7.

7. Aoyama K, Takenaka I, Sata T, Shigematsu A. Cricoid pressure impedes positioning and ventilation through the laryngeal mask airway. Can J Anaesth 1996; 43:1035-40. https://doi.org/10.1007/BF03011906 PMid:8896856

8. Palmer JH, Ball DR. The effect of cricoid pressure on the cricoid cartilage and vocal cords: an endoscopic study in anaesthetized patients. Anaesthesia 2000; 55:263-68. https://doi.org/10.1046/j.1365-2044.2000.01207.x

9. Takashi Asai. Videolaryngoscopes. Do they truly have roles in difficult airway. Anesthesiology 2012; 116:515-7. https://doi.org/10.1097/ALN.0b013e318246e866 PMid:22261794

10. Paolini JB, Donati F, Drolet P.Videolaryngoscopy: another tool for difficult intubation or a new paradigm in airway management? Can J Anaesth. 2013; 60:184-91. https://doi.org/10.1007/s12630-012-9859-5 PMid:23233395

11. Karalapillai D, Darvall J, Mandeville J, Ellard L, Graham J, Weinberg L. A review of videolaryngoscopes relevant to intensive care unit. Indian J Crit Care Med. 2014: 18;442-52. https://doi.org/10.4103/0972-5229.136073 PMid:25097357 PMCid: PMC4118510

12. Maharaj CH, Costello JF, Harte BH, Laffey JG. Evaluation of the Airtraq ${ }^{\circledR}$ and Macintosh laryngoscopes in patients at increased risk for difficult tracheal intubation. Anaesthesia 2008; 63: $182-8$.

https://doi.org/10.1111/j.1365-2044.2007.05316.x PMid:18211450

13. Levitan RM, Kinkle WC, Levin WJ, Everett WW. Laryngeal view during laryngoscopy: A Randomized trial comparing cricoid pressure, backward upward-rightward pressure, and bimanual laryngoscopy. Ann Emerg Med 2006; 47:548-55. https://doi.org/10.1016/j.annemergmed.2006.01.013 PMid:16713784

14. Oh J, Lim T, Chee Y, Kang H, Cho Y, Lee J, et al. Videographic analysis of glottic view with inreasing 
cricoid pressure force. Ann Emerg Med 2013; 61:407-13.

https://doi.org/10.1016/j.annemergmed.2012.10.038 PMid:23306455

15. Kumar N, Behera D, Dali JS, Arya M, Gupta A. Cricoid pressure with the Truview Evo2TM laryngoscope improves the glottic view. Can J Anesth 2011; 58:810-14.

https://doi.org/10.1007/s12630-011-9543-1

PMid:21691934

16. Corda DM, Riutort KT, Leone AJ, Qureshi MK, Heckman MG, Brull SJ. Effect of jaw thrust and cricoid pressure maneuvers on glottic visualization https://doi.org/10.1097/EJA.0b013e32832e9a32

PMid:19571760 during Glidescope videolaryngoscopy. J Anesth 2012; 26:362-68.

https://doi.org/10.1007/s00540-012-1339-0

PMid:22410965

17. Riad W, Ansari T. Effect of cricoid pressure on the laryngoscopic view by Airtraq ${ }^{\circledR}$ in elective caesarean section: a pilot study. Eur J Anaesth 2009; 26:981-82.

18. Ochroch EA, Hollander JE, Levitan RM. POGO score as a predictor of intubation difficulty and need for rescue devices. Ann Emerg Med. 2000; 36: A199. 